\section{EL SEGURO EN EL CAMPEONATO MUNDIAL DE FUTBOL DE 1982}

\author{
José M. ${ }^{a}$ Navas Borrego \\ Ingeniero de Caminos \\ SCOR, España
}

\section{Introducción}

Un campeonato mundial de fútbol es un aconte cimiento que mueve en torno suyo multitud de actividades, entre las que inevitablemente se en cuentra el Seguro, que entra en acción cubriendo las más variadas garantias. A título orientativo, mencionemos los seguros que la FIFA concierta de acuerdo con sus estatutos:

a) Perjuicios por anulación

b) Responsabilidad civil del organizador y realizador

c) Responsabilidad civil por perjuicios patrimo niales

d) Accidentes (incluso enfermedad)

e) Defensa juridica

f) Equipaje

g) Espectadores (incluso muerte por fallo cardíaco)

h) Aparatos (instalaciones de baja tensión)

Además, la Federación Española y el Real Comité Organizador conciertan un seguro de estadios y otra serie que, en parte, repite la relación anterior de la FIFA, con algunas novedades como:

- la propia Copa que está en juego;

- asalto de cobradores;

- robo e incendio de entradas;

- perjuicios causados por personas de confianza;

- vehiculos de motor.
De toda esta variopinta gama, el seguro que más interés presenta para una revista como INFORMES es, indudablemente, el que cubre los trabajos de construcción o remodelación de los estadios donde tendrán lugar los encuentros, seguro que se denomina de Todo Riesgo Construcción, cuyas principales características vamos a exponer a continuación.

\section{Seguro todo riesgo construcción}

Este seguro cubre a las entidades o personas que intervienen en la obra. Generalmente, los asegurados suelen ser el contratista y/o la propiedad.

La poliza asegura no solamente bienes propios, sino que puede y suele cubrir también responsabilidades. Analicemos unos y otras:

a) Seguro de bienes proplos, que comprende cuatro clases:

- La propia obra, es decir, los trabajos permanentes y temporales realizados y en curso de realización. Estos conceptos incluyen también los materiales, aprovisionamientos y repuestos necesarios para la obra asegurada, asi como los gastos de desescombro hasta un porcentaje (del orden del $5 \%$ ) del valor asegurado.

- Equipo de construcción, es decir, los elementos que, sin formar parte de la obra, son precisos para ejecutarla, tales como: andamios, entibaciones, herramientas, desagües, combustibles, edificaciones provisionales, etc.

- Maquinaria de construcción: grúas, hormigoneras, excavadoras, compresores, etcétera. (Advirtamos que la maquinaria puede tener una cobertura más amplia en las póm lizas de Avería de Maquinaria).

- Efectos personales de los empleados y obreros.

El valor de todos estos bienes figura en la póliza. 
b) Seguro de responsabllidades. En concreto, se refiere a la responsabilidad civil extracontractual, quedando lógicamente fuera de cobertura la responsabilidad civil de tipo contractual y todo tipo de responsabilidad penal. Esta garantia cubre las indemnizaciones que el asegura. do deba satisfacer a terceros como responsable civil por daños accidentales causados a los mismos y directamente relacionados con la ejecución de la obra. Se cubren tambien las costas y gastos judiciales y la prestación de fianzas. Pueden también cubrirse la responsabilidad patronal y la denominada responsabilidad cruzada (caso de actuación simultánea de diversos contratistas o subcontratistas).

Se indica en la póliza el importe máximo a que pueden llegar estas garantias.

Conviene resaltar la importancia de esta co bertura de responsabilidad civil derivada de la obra, en los casos que ahora estamos considerando de remodelación de estadios que han sequido funcionando durante la mayor parte del periodo de obras. Pensemos, por ejemplo, en los cuantiosos daños a terceros que hubie ra podido ocasionar el hundimiento, durante la celebración de un encuentro, de parte de las marquesinas que se han construido para cubrir los graderios del Bernabéu o del Nou Camp.

c) Seguro de bienes preexistentes. Es esta una garantia en cierto modo hibrida de las dos an teriores. En efecto: el bien preexistente que se asegura (por ejemplo, la primitiva estructura del Bernabéu, que se ha debido reforzar parcialmente por apoyar sobre ella una nueva obra) no forma parte de la obra a realizar, por lo que no entra en el apartado de "bienes pro plos", pero tampoco entra en el de "responsabilidades", como pudiera parecer a primera vista, porque la forma de garantía no es de este tipo (en el que hay que demostrar la responsabllidad nexo causamefecto) sino del tipo "daños" (en el cual basta la aparición del daño para que el seguro indemnice) y porque, además, en muchos casos estos bienes preexistentes no pueden tener la consideración de "terceros", para que actúe la cobertura de responsabilidad civil.

Parece innecesario insistir sobre el interés que este apartado tiene en nuestro caso.

\section{Riesgos cubiertos}

Veamos ahora cuáles son los riesgos cubiertos. En principio, todos, salvo los expresamente ex- cluidos, siempre que los daños o pérdidas mate riales producidos sean consecuencia directa de una causa accidental e imprevisible y se presenten de forma súbita.

Entre las principales causas de siniestros, las hay externas a las obras, como inundaciones, huracam nes, terremotos, caida del rayo, robo, corrimienm tos de terrenos, etc., y las hay originadas por la propia ejecucion de los trabajos, como incendios, hundimientos de obras construidas, choques durante los desplazamientos de piezas, rotura durante los ensayos, etc.

Los riesgos excluidos (origen de suspicacias poco undamentadas) comprenden algunos casos de fuerza mayor (guerra, explosión nuclear) algunos conceptos inasegurables (como actos voluntarios del asegurado) y algunos riesgos que frecuente mente se "repescan" en las condiciones particulares de la póliza (como error de diseño o ejecución, o utilización de materiales defectuosos) 0 bien se aseguran en otros tipos de póliza (vehiculos, etcétera).

El seguro tiene validez durante el periodo indicado en la póliza, que es el previsto para la realización de los trabajos (si se producen retrasos, se pro rroga el plazo mediante una sobreprima). También se puede asegurar un periodo de mantenimiento, durante el cual las garantias cubiertas son:

- Los daños ocasionados por el contratista con motivo de la ejecución de trabajos de mante nimiento, siempre que estos daños no esten excluidos.

- Los daños que tengan su origen en el periodo de obras (siempre que no estén excluidos) y que se manifiesten durante el periodo de mantenimiento.

- Alguna vez (aunque es poco frecuente), la garantia se extiende incluso a los fabricantes de las plezas prefabricadas que se instalen.

Como es probable que algún lector sienta curiosidad por saber cómo se procede a la indemnización, caso de ocurrir un siniestro (curiosidad quizás teñida de escepticismo), vamos a explicarlo rápidamente.

Una vez que se ha comprobado que el siniestro está cublerto por las garantias de la póliza, se procede a la valoración de los daños (la póliza prevé la resolución de los casos de litigio) partiendo del valor, en el dia del siniestro, de los bienes siniestrados; y se abona su importe, previa 
deducción de la correspondiente franquicia establecida para cada concepto.

Es importante subrayar el hecho de que se opera con los valores en el dia del siniestro, lo cual supone que los valores declarados a la suscrip. ción de la póliza deben ser regularmente revisados durante el periodo de obra, a fin de evitar desfases entre los valores de siniestros potenciales y los de referencia. Caso de que este destase se presente, se aplica la denominada "regla propor cional" de forma que si resulta que el valor de una o más partidas, tomadas separadamente, es superior a la respectiva suma asegurada, el asegum rado se convierte en su propio asegurador por el exceso.

Un pequeño ejemplo acabará de aclararlo: una cosa que vale 100 sufre un daño parcial que se valora en 30, habiendo una franquicia de 5 . Si en la póliza figura 100 como valor de la cosa, se indemniza la totalidad del siniestro menos la franquicia, es decir, 25. Pero si en la póliza figurase 80 como valor de esa cosa, el asegurado es su proplo asegurador en un $20 \%$, con 10 que la in- demnización seria sólo del $80 \%$ del valor del si niestro, menos la franquicla, es decir, 19. A Atención, pues, a esta circunstancia! Es causa de mum chos disgustos tan evitables como improcedentes.

La franquicia suele ser un punto de friccion a la hora de firmar la poliza, por la resistencia que el asegurado opone habltualmente a su establecim miento o, al menos, a la cuantía de la misma, que considera elevada.

No es esta ocasión para justificar la existencia de las tranquicias en las pólizas de construcción, pero son necesarias. Me brindo gustosamente, si la Dirección de la Revista lo considera Interesante y los lectores lo soportan, para escribir un articulo explicando este tema.

Para finalizar, digamos que el costo de estos se guros (variable en función de la complejidad de las obras, de su duración, de la cuantía de las garantias de responsabilidad y de preexistentes, de la franquicia, etc.) ha sido del orden del tres por mil del valor de la obra.

\section{CUADRO RESUMEN DE LAS PRINCIPALES GARANTIAS}

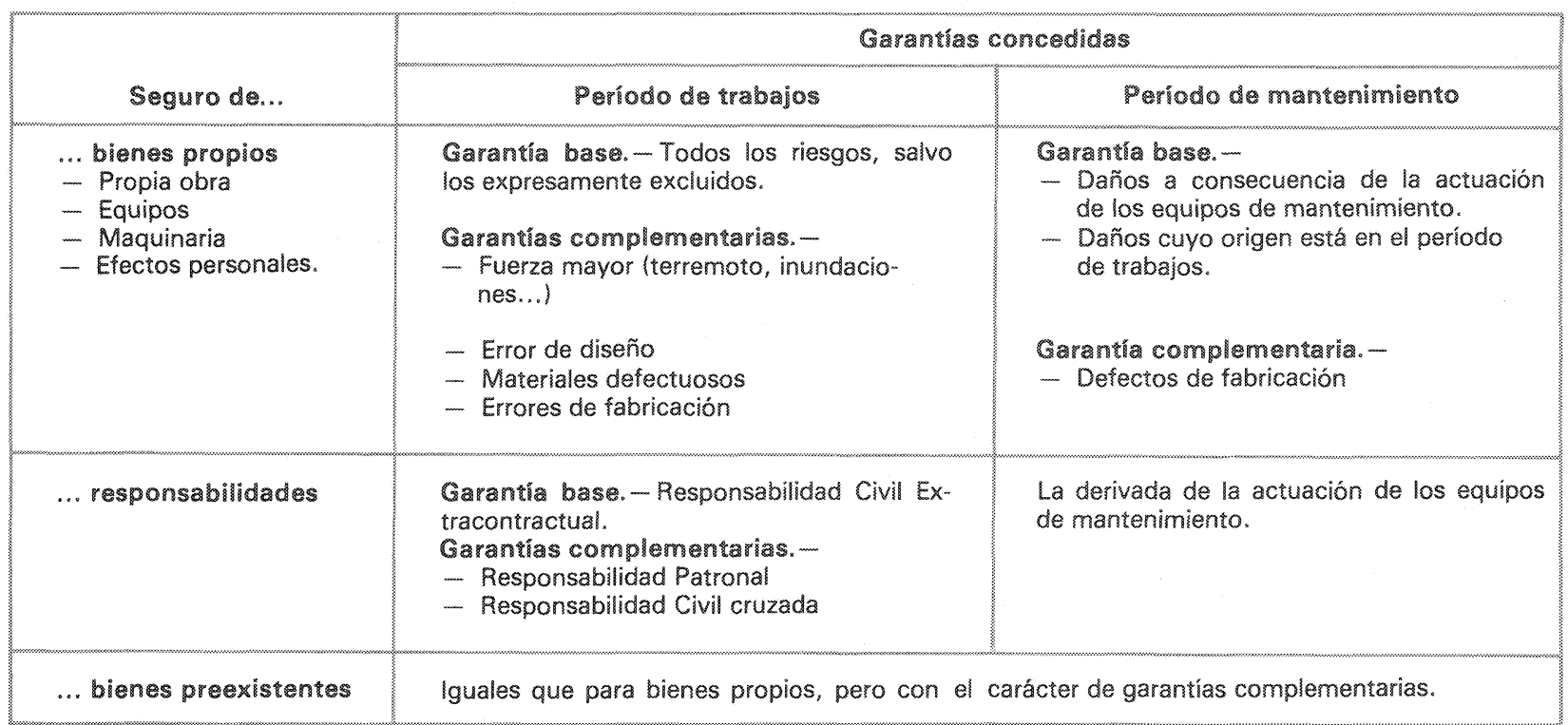

\section{$* * *$}

